Research Paper:

\title{
The Effectiveness of Cognitive Behavioral Therapy
}

on Marital Intimacy and Identification of the Basic

Psychological Needs Among Couples Referring to

Counseling Centers

\author{
Zahra Ebadi $^{1}$ (D, Reza Pasha ${ }^{1^{*}}$ (D) Fariba Hafezi ${ }^{1}$ (D) Zahra Eftekhar ${ }^{1}$
}

1. Department of Psychology, Ahvaz Branch, Islamic Azad University, Ahvaz, Iran.

Crtation Ebadi Z, Pasha R, Hafezi F, Eftekhar Z. The Effectiveness of Cognitive Behavioral Therapy on Marital Intimacy and Identification of the Basic Psychological Needs Among Couples Referring to Counseling Centers. Avicenna J of Neuropsychophysiology. 2018; 5(4):189-196. http://dx.doi.org/10.32598/ajnpp.4.3.290

doliohttp://dx.doi.org/10.32598/ajnpp.4.3.290

(c) (1) (8)

Article info:

Received: 05 May 2018

Accepted: 17 Sep 2018

Available Online: 01 Nov 2018

Keywords:

Cognitive-behavioral psychotherapy, Marital intimacy, Basic needs of couples

\section{ABSTRACT}

Introduction: If couples do not acquire communication and conflict resolution skills, their disagreements will continue at first verbally and then behaviorally. Thus, the gradual destruction in marital intimacy will begin.

Objectives: This study aimed to investigate the effectiveness of cognitive-behavioral psychotherapy on the couple's intimacy and identification of basic psychological needs in couples referring to counseling centers.

Materials and Methods: This is a quasi-experimental study with a Pre-test-Post-test design and control group. The study population consisted of all couples referring to counseling centers of Ahvaz City, Iran, in the year 2018-2019. The sample was recruited with a convenience sampling method consisting of 40 couples that were randomly assigned to the experimental and control groups (20 in each group). To collect information, we used Thompson and Walker's (1983) marital intimacy scale and Glaser basic need questionnaire. The experimental group underwent cognitive-behavioral psychotherapy (eight 90-minute sessions), but the control group received no intervention. The data were analyzed using descriptive and inferential statistics (repeated measure ANOVA).

Results: The cognitive-behavioral psychotherapy was effective in increasing marital intimacy and identifying the basic needs of the couples $(P<0.05)$.

Conclusion: Based on the results, cognitive-behavioral psychotherapy was effective in improving the intimacy and identification of basic needs in couples of couples referring to counseling centers.

\section{* Corresponding Author:}

Reza Pasha, PhD.

Address: Department of Psychology, Ahvaz Branch, Islamic Azad University, Ahvaz, Iran.

Tel: +98 (915) 1950664

E-mail: g.rpasha@yahoo.com 


\section{Introduction}

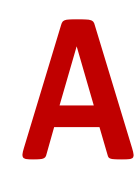

Society and a healthy family depend on satisfying marital relationships. Conflicts between couples should not only make the family system unstable but also develop affections between them and leads to the social and subsequent adjustment of couples. So, marital relationships can, on the one hand, be the greatest human pleasures, and on the other hand, the greatest sources of suffering in couples [1]. Undoubtedly, the family institution plays a determinative role in forming the ideas, thoughts, and beliefs of individuals. Whenever this institution has positive and adaptive functions, society certainly takes the path of progress [2]. However, because some couples have poor communication and martial skills, the functions of the family institution disrupt and efforts should be made to prevent interruptions in couples' relationships [3]. Thus, the sign of social life is a constructive relationship with the expression of the partner's love, affection, and intimacy [4]. One of the factors that bring satisfaction in marital relationships is intimacy.

Intimacy means feeling the similarity and proximity of a loving personal relationship with another person, which requires awareness, acceptance, understanding, and expressing emotions [5]. Intimacy in couples' relationships is one of the emotional needs of marital relationships, which leads to the consolidation of affectionate relationships between them [6]. Couples with high marital intimacy express their needs effectively and easily fall into the emotions and opinions of their partners [7].

Bagarozi, in his research, showed that the crucial factor in creating a permanent marriage is the existence of intimacy between couples [8]. On the other hand, avoiding intimate and enjoyable relationships causes failure in family life. Also, Mahdipour Bazkiani and Sedghatifard reported a significant relationship between marital satisfaction and couples' intimacy with their adjustment capability [9]. In other words, intimacy is one of the fundamental factors in the satisfaction or dissatisfaction of partners with their marital life, because it strengthens the couples' commitment to the relationship and predicts the compatibility and prosperity of the relationship [5].

One of the factors that may help create marital intimacy is to identify the basic needs of the couple. Glaser has seriously discussed basic needs as the reality therapy approach or theory of choice [10]. The needs of love and belonging, power (achievement/competency), freedom (independence), and fun (enjoyment) are considered basic psychological needs, and the need for survival is the only basic physiological need in humans [11]. These five basic needs are common to all people, but the importance and priority of each vary from person to person. In every person, one or some of these needs are more important than the others [12]. According to choice theory, people's consciousness of the unique pattern of their basic needs is crucial in making healthy and constructive choices in their personal and social lives [13]. If these needs are met satisfactorily, the person will have a pleasant feeling, but if meeting these needs fails, the individual will suffer from unpleasant emotions [14].

Many studies have examined the relationship between basic needs and couple relationships. Vaziri showed that love and attachment need boost marital satisfaction, while freedom opposes marital satisfaction. In this regard, there are different approaches toward couple therapy that emphasize various aspects of couple problems, one of which that focuses on the enrichment of cognition and behavior between couples is cognitive-behavioral psychotherapy [15]. In recent years, researchers have paid more attention to the role of cognitive factors in understanding the dynamics of interactions in marital relationships. Cognitive-behavioral therapy programs are based on a type of behavioral therapy that has emerged within traditional psychotherapy positions and reflects the growing interest of therapists to modify cognition as a factor influencing emotions and behaviors [16]. The purpose of this therapy is to correct irrational beliefs, dysfunctional beliefs, misconceptions, and cognitive errors, to control life, to facilitate constructive self-talk, and to enhance coping skills [17].

To make couples' relationships more enjoyable, marital counseling as professional counseling can be a good solution and give the couples the information needed to increase their knowledge and awareness of issues affecting marital relationships. Marital counseling emphasizes the power of conflict resolution and communication to promote marital intimacy [18]. This consultation relates to the cognitive domain (information and knowledge), emotional domain (feelings, values, attitudes), and behavioral domain (communication and decision making skills) [19]. The cognitive-behavioral approach considers the main cause of marital problems as negative interactions and communication failure of couples [20]. Counseling with the cognitive-behavioral approach helps clients develop skills to change behavior, communicate with others, solve problems, change non-useful 
beliefs and attitudes, and reconstruct their cognitive [21]. Cognitive-behavioral education and counseling can improve the family status and increase marital satisfaction by enhancing communication skills and positive thinking.

Literature supports that the treatment approach is effective in the field of marital relations and deals with different aspects of this relationship [22]. Also, previous results show that cognitive-behavioral therapy had a significant impact on the intimacy and marital satisfaction of betrayed women [19] and has a significant effect on increasing marital satisfaction, especially in improving communication and marital conflict, marital burnout resolution skills of couples, and their sexual relationships $[23,24]$. Also, this approach is effective in enhancing marital satisfaction and sexual satisfaction in postmenopausal women [25] and is effective in improving women's quality of life and happiness [26, 27].

In general, marital counseling is one of the most remarkable ways of solving problems and achieving intimacy and the basic needs of couples to improve and manage their marital relationship. Understanding these factors will help both family therapists and counselors to identify problems and help couples to identify, create, strengthen, or modify them to meet their basic needs. Given the rising rate of divorce in the country, where behavioral and communication problems are the most important factors in life and the adverse impact of behavioral problems on the lives of couples and other family members, it is necessary to recognize and apply effective solutions in this regard. Thus, we investigated the effectiveness of cognitive-behavioral psychotherapy on marital intimacy and identify basic psychological needs among couples referred to counseling centers in Ahvaz City, Iran.

\section{Materials and Methods}

This is an applied study with a Pretest-Posttest quasiexperimental design and a control group. The study population included all couples referred to counseling centers in Ahvaz City in 2017. In this study, 40 couples who scored lower than the average in marital intimacy and identifying basic needs (based on the questionnaire used in this study) were selected as the research sample and randomly assigned to the experimental and control group (20 people in each group). The inclusion criteria included drug abuse, inexperience in the previous divorce, divorce litigation, lack of physical and psychological illness. The exclusion criteria included missing more than two sessions of intervention sessions, being under another treatment simultaneously with this intervention, and taking any particular medication.
After selecting couples referring to Ahvaz eligible counseling centers, the Pre-test was done for all, and then the experimental group received cognitive-behavioral psychotherapy intervention while the control group did not receive any intervention (Table 1 ). After the therapy sessions, the experimental and control groups underwent the same Post-test, and both groups were followed up one month after the Post-test. After collecting Pre-test, Post-test, and follow-up data, they were analyzed with appropriate statistical tests, including repeated measures ANOVA in SPSS version 24. Also, after the follow-up phase, intensive cognitive-behavioral psychotherapy sessions were held for the control group to comply with the ethical principles.

\section{Data gathering tools}

\section{Marital intimacy}

Marital intimacy was measured using two scales [28] with six items for positive (Cronbach's alpha $=0.90$ ) and five items for negative intimacy (Cronbach's alpha= 0.83). Example items are, "How much does/did your spouse or partner really care about you?" (Positive) and "How often does/did your spouse or partner make you feel tense?" (Negative). Responses ranged from not at all $(=1)$ to a lot $(=4)$ [4]. The marital intimacy of the study participants was assessed via the Iranian version of Bagarozzi's marital intimacy needs questionnaire [8]. It contains 41 items scored based on a 10-point Likerttype scale. There are eight dimensions of intimacy: emotional, psychological, intellectual, sexual, physical, spiritual, aesthetic, and social. The Cronbach's alpha of reliability for the tool was 0.94 . In a similar study in Iran, the Cronbach's alpha measurement was 0.92 [29].

\section{Basic psychological need scale}

La Guardia et al. [30] developed this scale, and Ghorbani and Watson [31] adapted it for Iranian users. It is composed of 21 items used to assess three subscales of autonomy satisfaction (7 items), competence satisfaction (6 items), and relatedness satisfaction (8 items). Responses were rated based on a 7-point Likert-type scale, from not true at all $(=1)$ to very true $(=7)$. This scale does not have a cutoff point, and a high score indicates psychological need satisfaction. The validity of this scale on Iranian managers and students have been reported between 0.76 and 0.79 [32]. In the present study, the Cronbach alpha reliability coefficient was found 0.81 for love and belonging, 0.77 for power, 0.79 for freedom, 0.78 for survival, and 0.81 for fun. 
Table 1. Cognitive-behavioral couple therapy protocol (8 therapeutic sessions)

\begin{tabular}{|c|c|}
\hline No. & Sessions \\
\hline 1 & $\begin{array}{l}\text { Establishing a good relationship with the couple, explaining the rules, objectives, and number of sessions, individual, } \\
\text { and joint assessments, as well as implementing the Pre-test. }\end{array}$ \\
\hline 2 & $\begin{array}{l}\text { Introducing treatment process, evaluate, and determine main objectives, identifying concerns and variables influ- } \\
\text { encing the couple's infidelity and focus on the ways to increase love and affection. }\end{array}$ \\
\hline 3 & $\begin{array}{c}\text { Emphasize and focus on the adoption and use of problems to increase intimacy dimensions. Discuss the impact of } \\
\text { cognitive errors on their partners' behavior and relationship, scrutiny of negative patterns, reproach, and blame, } \\
\text { threatening to leave the relationship, identify specific spouse's basic needs in marital life. }\end{array}$ \\
\hline 4 & $\begin{array}{l}\text { Teaching cognitive patterns to couples, focusing on increasing couples' tolerance so that they finish their challenges } \\
\text { sooner. Identifying couples' cognitive errors through Socratic questioning. Assignments for home. }\end{array}$ \\
\hline 5 & $\begin{array}{l}\text { Identifying irrational thoughts and beliefs and challenging them as ways to question and ultimately change their } \\
\text { thoughts. }\end{array}$ \\
\hline 6 & $\begin{array}{l}\text { Make plans to do pleasant activities, express positive characteristics of each other, exchange behavior, increase } \\
\text { individual activities, teaching communication skills, active listening skills training, expressing certain behavioral } \\
\text { expectations, doing homework. }\end{array}$ \\
\hline 7 & $\begin{array}{c}\text { Train and practice problem-solving techniques, assertiveness training, and timing and planning to carry out activi- } \\
\text { ties, teach emotional skills. } \\
\text { Emotional awareness training and its role in family life, teach ways of solving surmountable problems, and provide } \\
\text { training that helps couples to identify their style of starting the dispute. }\end{array}$ \\
\hline 8 & $\begin{array}{l}\text { Explain the effects of psychological factors on sexual function, teach sexual disorders briefly, and teach how to } \\
\text { increase emotional tolerance during marital interaction, ways of overcoming permanent and insurmountable prob- } \\
\text { lems. } \\
\text { Summarize the previous subjects, assess the client's feedback to sessions and results, perform the Post-test, and } \\
\text { end of sessions. }\end{array}$ \\
\hline
\end{tabular}

AJNPP

\section{Results}

Before applying the repeated measures analysis of variances test, Levene's test was conducted to ensure the homogeneity of research variables and the Shapiro and Wilk test for analyzing the normal distribution of research variables.

Data were analyzed with a mixed-design analysis of variance according to the 3 measurement times. To this end, the M Box test was used to ensure the observation of this test assumption (i.e. the equality of variancecovariance matrices across the cells was formed by the between-subject's effects), which rejected the null hypothesis of this assumption.

However, considering the equal size of the sample groups, mixed-design analysis of variance is strong to the contravention of this assumption. Then, the assumption of sphericity was performed for all variables using the Muchly's test, but the outcome illustrates that this assumption has not been observed. Therefore, the Greenhouse-Geisser test was used to improve the degrees of freedom in the analysis of variance. The results showed that the significance of the measurement time effect (pre-test, post-test, follow-up) on the intimacy variable matches the group fellowship type of the couples $\left(F_{2}=0.172, P<0.05\right)$. Mean and standard deviation of experimental and control group research variables is showed in table 2 .

In addition, regarding the identification of psychological basic needs component, the results of Muchly's test showed compliance with this assumption (W Muchly's love and belonging $=0.172, \mathrm{P}<0.05 ; \mathrm{W}$ Muchly's power $=0.122, \mathrm{P}<0.05 ; \mathrm{W}$ Muchly's freedom = 0.237, $\mathrm{P}<0.05$; $\mathrm{W}$ Muchly's survival $=0.192, \mathrm{P}<0.05 ; \mathrm{W}$ Muchly's fun $=0.551, \mathrm{P}<0.05)$, indicating no need to modify the degrees of freedom in the analysis of variance. The results of ANOVA with the sphericity assumption showed a significant difference between marital intimacy and the identification of basic psychological needs of the experimental and control groups in the 3 measurement times (pre-test, post-test, follow-up) (Table 3).

As seen in Table 4, all tests indicate a significant difference between the studied groups in at least one of the dependent variables (marital intimacy, the identification of psychological basic needs). Therefore, the answer is yes to the question of whether cognitive-behavioral psychotherapy is effective on marital intimacy and identifying basic psychological needs among couples referred to counseling centers in Ahvaz. 
Table 2. Mean and standard deviation of experimental and control group research variables in the Pre-test, Post-test, and follow-up

\begin{tabular}{|c|c|c|c|}
\hline \multirow{2}{*}{ Variables } & \multirow{2}{*}{ Groups } & \multicolumn{2}{|c|}{ Mean \pm SD } \\
\hline & & Intervention & Control \\
\hline \multirow{3}{*}{ Marital intimacy } & Pre-test & $1.84 \pm 52.35$ & $1.92 \pm 52.30$ \\
\hline & Post-test & $1.84 \pm 67.35$ & $3.36 \pm 52.65$ \\
\hline & Follow-up & $1.81 \pm 68.58$ & $3.01 \pm 52.59$ \\
\hline \multirow{3}{*}{$\begin{array}{l}\text { Identifying basic psychological needs (love } \\
\text { and belonging) }\end{array}$} & Pre-test & $1.15 \pm 9.20$ & $1.48 \pm 8.90$ \\
\hline & Post-test & $1.05 \pm 14.05$ & $1.29 \pm 9.10$ \\
\hline & Follow-up & $1.11 \pm 14.47$ & $1.17 \pm 9.15$ \\
\hline \multirow{3}{*}{$\begin{array}{l}\text { Identifying basic psychological needs } \\
\text { (power) }\end{array}$} & Pre-test & $1.80 \pm 8.95$ & $0.98 \pm 9.35$ \\
\hline & Post-test & $1.57 \pm 14.75$ & $0.94 \pm 9.55$ \\
\hline & Follow-up & $1.48 \pm 15.73$ & $0.96 \pm 9.52$ \\
\hline \multirow{3}{*}{$\begin{array}{l}\text { Identifying basic psychological needs } \\
\text { (freedom) }\end{array}$} & Pre-test & $1.61 \pm 8.75$ & $1.71 \pm 8.30$ \\
\hline & Post-test & $1.70 \pm 12.20$ & $1.70 \pm 9.20$ \\
\hline & Follow-up & $1.58 \pm 13.42$ & $1.70 \pm 9.21$ \\
\hline \multirow{3}{*}{$\begin{array}{l}\text { Identifying basic psychological needs } \\
\text { (survival) }\end{array}$} & Pre-test & $1.46 \pm 8.85$ & $1.59 \pm 8.85$ \\
\hline & Post-test & $1.23 \pm 14.40$ & $1.98 \pm 8.50$ \\
\hline & Follow-up & $1.13 \pm 15.14$ & $1.92 \pm 8.65$ \\
\hline \multirow{3}{*}{ Identifying basic psychological needs (fun( } & Pre-test & $1.75 \pm 8.80$ & $1.70 \pm 8.80$ \\
\hline & Post-test & $1.73 \pm 13.30$ & $1.94 \pm 7.90$ \\
\hline & Follow-up & $1.69 \pm 14.21$ & $1.94 \pm 7.92$ \\
\hline
\end{tabular}

Table 3. The results of the Muchly's intimacy spherical test and the identification of psychological basic needs

\begin{tabular}{ccccc}
\hline Variables & Muchly's Sphericity & Chi-square & df & P \\
\hline Marital intimacy & 0.172 & 77.513 & 2 & 0.001 \\
\hline Identifying basic psychological needs (love and belonging) & 0.172 & 77.513 & 2 & 0.001 \\
\hline Identifying basic psychological needs (power) & 0.122 & 92.639 & 2 & 0.001 \\
\hline Identifying basic psychological needs (freedom) & 0.237 & 63.303 & 2 & 0.001 \\
\hline Identifying basic psychological needs (survival) & 0.192 & 72.627 & 2 & 0.001 \\
\hline Identifying basic psychological needs (fun) & 0.551 & 26.191 & 2 & 0.001 \\
\hline
\end{tabular}

AJNPP

\section{Discussion}

This study aimed to investigate the effectiveness of cognitive-behavioral psychotherapy on marital intimacy and identifying basic psychological needs among couples referred to counseling centers in Ahvaz. The results show that cognitive-behavioral training has been effective in marital intimacy and identifying basic psychological needs among couples. These results are in line with the findings of Mohaddassi et al. [19], Karimi and Khalatbari [21], Bagheri and Samsam Shariat [22], Ehsan Nejad et al. [25], Pourmusa et al. [27], and Hummel et al. [18].

To explain these results, it can be said that communication issues and couples' poor skills in companionship are the most significant factors in producing conflict, dissatisfaction, and incompatibility, which result in the 
Table 4. Summary of variance analysis of frequent measures of marital intimacy and identification of basic needs

\begin{tabular}{|c|c|c|c|c|c|}
\hline Variables & Resource of Change & $\mathbf{F}$ & $\mathbf{P}$ & Effect Size & Statistical Power \\
\hline \multirow{3}{*}{ Marital intimacy } & Time & 87.421 & 0.001 & 0.574 & 0.999 \\
\hline & Group & 25.617 & 0.001 & 0.423 & 0.999 \\
\hline & Time and group interaction & 18.476 & 0.001 & 0.354 & 0.999 \\
\hline \multirow{3}{*}{$\begin{array}{l}\text { Identifying basic psycho- } \\
\text { logical needs (love and } \\
\text { belonging) }\end{array}$} & Time & 97.521 & 0.001 & 0.674 & 0.999 \\
\hline & Group & 23.647 & 0.001 & 0.523 & 0.999 \\
\hline & Time and group interaction & 19.466 & 0.001 & 0.454 & 0.999 \\
\hline \multirow{3}{*}{$\begin{array}{l}\text { Identifying basic psycho- } \\
\text { logical needs (power) }\end{array}$} & Time & 95.878 & 0.001 & 0.671 & 0.999 \\
\hline & Group & 7.104 & 0.001 & 0.245 & 0.914 \\
\hline & Time and group interaction & 11.337 & 0.001 & 0.345 & 0.992 \\
\hline \multirow{3}{*}{$\begin{array}{l}\text { Identifying basic psycho- } \\
\text { logical needs (freedom) }\end{array}$} & Time & 96.415 & 0.001 & 0.672 & 0.999 \\
\hline & Group & 11.421 & 0.001 & 0.347 & 0.990 \\
\hline & Time and group interaction & 13.031 & 0.001 & 0.357 & 0.998 \\
\hline \multirow{3}{*}{$\begin{array}{l}\text { Identifying basic psycho- } \\
\text { logical needs (survival) }\end{array}$} & Time & 87.955 & 0.001 & 0.652 & 0.999 \\
\hline & Group & 11.158 & 0.001 & 0.321 & 0.988 \\
\hline & Time and group interaction & 20.343 & 0.001 & 0.465 & 0.999 \\
\hline \multirow{3}{*}{$\begin{array}{l}\text { Identifying basic psycho- } \\
\text { logical needs (fun( }\end{array}$} & Time & 87.563 & 0.001 & 0.671 & 0.999 \\
\hline & Group & 11.769 & 0.001 & 0.353 & 0.991 \\
\hline & Time and group interaction & 18.359 & 0.001 & 0.429 & 0.999 \\
\hline
\end{tabular}

AJNPP

reduction of intimacy among couples. Providing couples with suitable and effective communication skills can lead to identifying basic needs which result in intimacy and satisfying marital life [33].

The cognitive-behavioral approach increases couples' awareness of their irrational thoughts and beliefs and also the positive aspects of their behaviors. Besides, through training sessions and homework assignments, this approach modifies the wrong beliefs and attributions. Modifying beliefs, unrealistic expectations, and false attributions of couples from each other reduces undue annoyance and increases understanding of positive aspects of each other's behavior, which eventually leads to increase marital intimacy. According to the cognitive approach followers, some common mental errors can mislead our interpretation of reality that displays themselves in our inappropriate behaviors.

Therefore, the depth of intimacy between two people in their relationship depends on their ability to transfer thoughts, feelings, needs, and demands clearly, correctly, and effectively. Cognitive-behavioral couple therapy can enhance communication skills such as ver- bal and nonverbal skills. The enhancement of communication skills increases positive self-confidence and reduces pessimism, which ultimately leads to improving intimacy and identifying basic psychological needs in married couples [34].

The program also provides couples with opportunities to practice new skills and receive feedback. Moreover, in this method, with assigning homework for the next sessions, the couples are obligated to practice their skills with themselves. Also, the homework will bring the couples closer together and enhances the intimacy between them and bring us happiness and welfare $[27-35,36]$.

This research, like other studies, has some limitations that need to be considered. First, caution must be taken in the generalization of the results because the samples were chosen with a convenience sampling method and only from one counseling center in one city. Second, this research could be done both quantitatively and qualitatively, but due to the lack of interview conditions, this approach was not possible in the present study. Similar research can be done in other cities with samples of dif- 
ferent cultures to overcome these limitations. Future research will use hybrid designs (qualitative and quantitative), a bigger sample size, and more sophisticated statistical methods that provide deeper analysis and better conclusions. Another limitation of the present study was using self-reporting tools. In future research, it is recommended to compare the methods of this research with other methods such as metacognition, reality therapy, and so on.

\section{Conclusion}

The results of this study indicate that cognitive therapy sessions are useful and applicable in raising happiness and providing couples with suitable and effective communication skills that can lead to identifying basic needs better and have intimacy and compatibility of marital life.

\section{Ethical Considerations}

\section{Compliance with ethical guidelines}

The participants provided their written consent. The designed therapeutic package was also implemented for the control group after the follow-up period.

\section{Funding}

The present paper was extracted from the PhD thesis of the first author, in the Department of Educational Psychology, Faculty of Educational Sciences and Psychology, Azad University of Ahvaz.

\section{Authors' contributions}

All authors equally contributed in preparing this article.

\section{Conflict of interest}

The authors declared no conflict of interest.

\section{References}

[1] Jafarbegloo E, Bakouei S, Dadkhahtehrani T. Marital satisfaction in menopausal women with and without sexual dysfunction. Journal of Midwifery and Reproductive Health. 2017; 5(4):1053-8.

[2] Lee YS. Marital satisfaction among korean commuter couples. Asian Journal of Social Science, 2018; 46(1-2):282-3. [DOI:10.1163/1568531404601009]
[3] Ebrahimi A, Momeni A. Explaining the effectiveness of the Imagotherapy approach and training of couples 'systematic communication program on increasing couples' compatibility, intimacy, and resilience in Bushehr. Journal of Psychological and Educational Sciences Studies. 2017; 17(17):178-65

[4] Holland KJ, Lee JW, Marshak HH, Martin LR. Spiritual intimacy, marital intimacy, and physical/psychological well-being: Spiritual meaning as a mediator. Psycholog Relig Spiritual. 2016; 8(3):218-27. [DOI:10.1037/rel0000062] [PMID] [PMCID]

[5] Naghdi Babaee Sh, Ghahari Sh. Effectiveness of communication skills training on intimacy and marital adjustment among married women. Research \& Health Sciences. 2016; 5(8):375-80.

[6] Kardan-Souraki M, Hamzehgardeshi Z, Asadpour I, Mohammadpour A, Khani SR. A review of marital intimacy-enhancing interventions among married individuals. Global Journal of Health Science. 2016; 8(8):74-93. [DOI:10.5539/gjhs.v8n8p74] [PMID] [PMCID]

[7] Masoumi SZ, Khani S, Kazemi F, Kalhori F, Ebrahimi R, Roshanaei Gh Effect of marital relationship enrichment program on marital satis faction, marital intimacy, and sexual satisfaction of infertile couples. International Journal of Fertility and Sterility. 2017; 11(3):197-204.

[8] Bagarozzi DA. Enhancing intimacy in marriage: A clinician's guide. $1^{\text {st }}$ ed. Oxfordshire: Routledge; 2001.

[9] Pour Bazkiani M, Sedaghati Fard M. The relationship between marital satisfaction and intimacy of couples with home adjustment. Journal of Analytical-Cognitive Psychology. 2015; 6 (22):21.

[10] Cappelletti ER, Kreuter MW, Boyum S, Thompson T. Basic needs, stress and the effects of tailored health communication in vulnerable populations. Health Education Research. 2015; 30(4):591-8. [DOI:10.1093/her/cyv033] [PMID] [PMCID]

[11] Kazemi S, Kakavand A, Jalali M, Javadi H. Relation Glasser's basic needs with hypertension in middle age: The mediating role of humor. The Journal of Qazvin University of Medical Sciences. 2018; 22(2):63-73. [DOI:10.29252/qums.22.2.63]

[12] Zarei E, Borumand R, Sadeghifard M, Najaripourian S, Askari M. Effectiveness of group counseiing based on choice theory on increasing intimacy and marital satisfaction and reducing marital conflicts in married women. Hormozgan Medical Journal 2017; 21(4):250-9. [DOI:10.29252/hmj.21.4.250]

[13] Purnell JQ, Kreuter MW, Eddens KS, Hannon P, Rebecca SW, Maria EF. et al. Cancer control needs of 2-1-1 callers in Missouri, North Carolina, Texas, and Washington. J Health Care Poor Underserved. 2012; 23(2):752-67. [DOI:10.1353/hpu.2012.0061] [PMID] [PMCID]

[14] Haushofer J, Fehr E. On the psychology of poverty. Science. 2014; 344(6186):862-7. [DOI:10.1126/science.1232491] [PMID]

[15] Vaziri M. The prediction of marital satisfaction based on basic needs in couples. Frooyesh. 2015; 4(3):87-96.

[16] Ussher JM, Perz J. Evaluation of the relative efficacy of a couple Cognitive-Behaviour Therapy (CBT) for Premenstrual Disorders (PMDs), in comparison to one-to-one CBT and a wait list control: A randomized controlled trial. PIOS One. 2017; 12(4):e0175068. [DOI:10.1371/journal.pone.0175068] [PMID] [PMCID]

[17] Vasa RA, Roy AK. Pediatric anxiety disorders: A clinical guide. New York: Springer Science and Business Medi. 2014. [DOI:10.1007/978 1-4614-6599-7]

[18] Hummel SB, Van Lankveld JJDM, Oldenburg HAS, Hahn DEE, Kieffer JM, Gerritsma MA. et al. Efficacy of internet-based cognitive be- 
havioral therapy in improving sexual functioning breast cancer survivors: Results of a randomized controlled trial. Journal of Clinica Oncology. 2017; 35(12):1328-40. [DOI:10.1200/JCO.2016.69.6021] [PMID]

[19] Mohaddessi H, Hamadani M, Khalkhali HR. The effect of cognitivebehavioral counseling on marital satisfaction of couples referred to selected health centers in Urmia, 2015. Journal of Urmia Nursing \& Midwifery Faculty. 2015; 14(8):747-38.

[20] Mazaheri MA, Sahebi A. The effect of cognitivebehavioral training on modification of irrational expectation, emotional maturity and marital dissatisfaction in women. International Journal of Behavioral Sciences. 2011; 5(2):127-33

[21] Karimi B, Khalatbari J. The effectiveness of cognitive-behaviora therapy on couple's burnout, marital adjustment and intimacy. Journal of Educational Psychology. 2017; 8(1):65-74.

[22] Bagheri Z, Samsam Shariat M. The effectiveness of cognitive behavioral therapy on intimacy and marital satisfaction in betrayed women. International Conference on Psychology, Education and Behavioral Sciences. 2016

[23] Shokrollahzadeh M, Forouzesh M, Bazrafshan MR, Hosseini H. The effect of cognitive behavioral couple therapy on marital conflicts and marital burnout. Family Pathology, Counseling and Enrichment Journal. 2017; 3(1):115-31.

[24] Dugal C, Bakhos G, Bélanger C, Godbout N. Cognitive-behaviora psychotherapy for couples: An insight into the treatment of couple hardships and struggles. Cognitive Behavioral Therapy and Clinica Applications, 2018; 3(2):125-35. [DOI:10.5772/intechopen.72104] [PMCID]

[25] Atema V, Van Leeuwen M, Oldenburg HSA, Retèl V, Beurden MV, Myra S. et al. An internet-based cognitive behavioral therapy for treatment-induced menopausal symptoms in breast cancer survivors: Results of a pilot study. BMC Cancervolume. 2016; 16:920. [DOI:10.1186/s12885-016-2946-1] [PMID] [PMCID]

[26] Shayan A, Taravati M, Garousian M, Babakhani N, Faradmal J, Masoumi SZ. The effect of cognitive behavioral therapy on marita quality among women. International Journal of Fertility and Sterility. $2018 ; 12(2): 99-105$

[27] Pourmousa H, Mohammadifar MA, Pesand ST, Rezaei AM. The effectiveness of intimacy training with cognitive-behavioral approach on couples' life quality and happiness. Electronic Journal of General Medicine. 2018; 15(6):em95. [DOI:10.29333/ejgm/93461]

[28] Ryff CC, Singer BH, Palmersheim KA. Social inequalities in health and well-being: The role of relational and religious protective factors. In: Grim O, Ryff C, Kessler R, ed. How Healthy Are We? A National Study of Well-being at Midlife. Chicago: University of Chicago Press; 2004.

[29] Pasha H, Basirat Z, Esmailzadeh S, Faramarzi M, Adibrad H. Marital intimacy and predictive factors among infertile women in northern Iran. Journal of Clinical and Diagnostic Research. 2017; 11(5):QC13 QC17. [DOI:10.7860/JCDR/2017/24972.9935] [PMID] [PMCID]

[30] La Guardia JG, Ryan RM, Couchman CE, Deci EL. Within-person variation in security of attachment: A self-determination theory perspective on attachment, need fulfillment, and well-being. Journal of Personality and Social Psychology. 2000; 79(3):367-84 [DOI:10.1037/0022-3514.79.3.367] [PMID]

[31] Ghorbani N, Watson PJ. Two facets of self-knowledge, big five and promotion among Iranian managers. Journal of Social Behavior and Personality. 2004; 6:769-77. [DOI:10.2224/sbp.2004.32.8.769]
[32] Mohammadi M, Salimi A, Zahrakar K, Davornia R, Shakrami M. Effectiveness of the relationship enrichment program on reduction of marital boredom of couples. Psychiatric Nursing Journal. 2016; 4(3):15-8 [DOI:10.21859/ijpn-04032]

[33] Honari A, Shamoli L. The effectiveness of cognitive behavioura couple therapy on marital stress and emotional skills of infidel couples in Shiraz. International Journal of Medical Research and Health Sciences. 2017; 6(2):83-90.

[34] Khojasteh Mehr R, Ahmadi Ghazloujeh A, Ghoozlucheh M, Shiralinia K. Effectiveness of short-term marital counseling on the emotional intimacy and marital quality of couples. Contemporary Psychology. 2015; 10(2):29-40.

[35] Nadimi M. Relationship between communication skills and deterministic thinking with marital satisfaction. Biological Forum - An International Journal. 2015; 7(2):33-39.

[36] Maleki N, Madahi ME, Mohammadkhani S, Khala'tbari J. The effectiveness of cognitive behavioral couple therapy on psychological well-being, marital intimacy, and life quality of chaotic couples. 2017; 1(4):23-33. 